\title{
POR UMA FILOSOFIA DE ENFRENTAMENTO DAS EPIDEMIAS (OU MANIFESTO CONTRA A SÍNDROME DE PAMPINEIA)
}

\section{BRIAN GORDON LUTALO KIBUUKA ${ }^{1}$}

RESUMO: Este artigo aborda a partir do motivo literário que serve de embreador para o Decamerão de Boccaccio, a temática do enfrentamento das epidemias. Apresenta-se neste artigo o desenvolvimento do que se tornará a filosofia moral e depois o utilitarismo em uma perspectiva crítica. Ao fim, destaca-se os mecanismos para a precarização da vida em situações pandêmicas e os meios para a superação de tal precarização, em favor dos direitos e da dignidade de cada pessoa humana.

PALAVRAS-CHAVE: Epidemias, Decamerão, Filosofia Moral.

ABSTRACT: This article deals with the literary motive that serves as a catalyst for Boccaccio's Decameron, the theme of facing epidemics. This article presents the development of what will become moral philosophy and later utilitarianism in a critical perspective. In the end, the mechanisms for the precariousness of life in pandemic situations and the means to overcome such precariousness in favor of the rights and dignity of each human person are highlighted.

KEYWORDS: Epidemics, Decameron, Moral Philosophy.

Decamerão, de Boccaccio, é uma obra que foi forjada sob o estigma da peste e sob o signo da reação filosófica a ela. Não é de se estranhar, portanto, que o embreador narrativo dessa obra seja, em um duplo sentido, a epidemia. Boccaccio escreveu a obra enquanto a peste atingia Florença, a partir de 1348. Em seu empreendimento literário, o autor florentino substituiu a imagem do naufrágio presente na antiga tradição mitológica relacionada aos acontecimentos trágicos, pela peste, que é citada, descrita e constitui a premissa situacional de Decamerão. ${ }^{2}$

A epidemia que atingiu Florença em 1348 e serviu de motivo da obra já era conhecida das autoridades da cidade desde o outono de 1347, quando rumores de que a Peste Negra já atingira outras cidades da Península Itálica provocou a adoção de medidas sanitárias e religiosas: as ruas da cidade foram limpas; viajantes e animais foram impedidos de entrar na cidade; as pessoas foram orientadas a ficar em casa; regulamentos higiênicos foram adotados

\footnotetext{
${ }^{1}$ Professor de História Antiga e Medieval da Universidade Estadual de Feira de Santana (UEFS). Doutorando em Filosofia pela Universidade Federal Fluminense (UFF). E-mail: bglkibuuka@uefs.br.

2 Sobre a relação entre a peste e o Decamerão, ver: LEVENSETIN, J. "Out of Bounds: Passion and Plague in Boccaccio's Decameron.” In: Italica 70 (3), 1996, p. 313-335; USHER, J. “Ars Moriendi in the Decameron.” In: The Modern Language Review 81 (3), 1986, p. 621-632.
} 
por comerciantes de alimentos; e procissões, orações, missas foram celebrados, bem como prostitutas e homossexuais foram expulsos de Florença no afã de aplacar a ira divina. ${ }^{3}$ Quando a doença começou a deixar as suas primeiras vítimas em março de 1348, Boccaccio foi testemunha do colapso da administração, dos ritos e da moral na cidade, e as impressões de tal testemunho estão evidentes em Decamerão. ${ }^{4}$

A epidemia não constitui em Decamerão apenas um motivo literário, como se o autor estivesse imbuído apenas da tarefa de salvaguardar algum legado intelectual da civilização humana contra as forças destruidoras de uma doença grave e devastadora. Para Boccaccio, a moral degenerada é um dos efeitos da peste, ${ }^{5}$ e é possível notar uma relação estabelecida pelo autor na obra entre o cataclismo e as condutas em uma dimensão moral. Em Decamerão, reagindo aos efeitos da pandemia, sete moças e dez jovens oferecem por meio de si mesmos a oportunidade de preservação e renovação do patrimônio intelectual e sociocultural florentino ao se deslocarem da cidade assolada pela peste e pela vida imódica para uma vila no campo. Ali, mediante o exercício da rememoração cuidadosa e metódica através do agrupamento de uma centena de novelas, os jovens apresentam miríades de elementos de uma cultura que corria o risco de ser extinta pela praga e pela imoralidade. Portanto, Decamerão narra o processo de preservação do legado florentino por meio das medidas tomadas por jovens, os quais constituem uma 'sociedade ideal' nas ruínas de Fiesole. 'Sociedade ideal' porque ela é veículo de uma renovação social por meio da adoção, pelos dez jovens de Boccaccio, de um rigoroso cronograma de atividades, de um código de conduta e do compartilhamento de conhecimentos e memórias. ${ }^{6}$

Boccaccio se projetou em sua obra como um amigo da humanidade, um Prometeu culto e sábio (Genealogie deorum gentilium 4.44.19-20) que adquire a luz da verdade pelo estudo diligente, que obtém a clareza de um sábio a ponto de obter redenção intelectual. ${ }^{7}$ Em Decamerão, ele oferece auxílio altruísta e filosófico por meio dos mitos e dos contos inovadores, e ele o faz com a diligência de um arquivista, a compreensão de um intelectual e o

\footnotetext{
${ }^{3}$ Sobre a Peste Bubônica em Florença e sobre as medidas sanitárias, ver: HENDERSON, J. “The Black Death in Florence: medical and communal responses". In: BASSETT, S. (ed.). Death in Towns: Urban Responses to the Dying and the Dead, 100-1600. New York: Leceister University Press, 1992, p. 127- 142.

${ }^{4}$ ANDREI, F. "Deified Men and Humanized Gods: The Epistemic Character of the Fabula." In: ANDREI, F. Boccaccio the Philosopher: An Epistemology of the Decameron. Cham: Palgrave Macmillan, 2017, p. 40 (p. 37 91). Sobre as implicações sociais da peste em Florença, ver: CARMICHAEL, A. G. Plague and the Poor in Renaissance Florence. Cambridge: Cambridge University Press, 1986.

${ }^{5}$ GITTES, T. F. Boccaccio's Naked Muse: Eros, Culture, and the Mythopoeic Imagination. Toronto: University of Toronto Press, 2016, p. 22-23, 142-143.

${ }^{6}$ GITTES, T. F. Boccaccio's Naked Muse: Eros, Culture, and the Mythopoeic Imagination. Toronto: University of Toronto Press, 2016, p. 152-154.

${ }^{7}$ MARINO, L. "Prometheus, or the Mythographer's Self-Image.” In: Studi sul Boccaccio 12, 1980, p. $263-273$.
} 
espírito criativo de um poeta. ${ }^{8}$ Sua obra é caracterizada por alegorizar a vida (como se observa, por exemplo, em Comedia delle ninfe fiorentine e em Amorosa visione) com o fim de suscitar uma teoria do conhecimento. Ainda que Boccaccio não seja filósofo no sentido tradicional, ${ }^{9}$ há uma filosofia em Decamerão, em que questões epistemológicas são apresentadas por meio do poder imaginativo de sua linguagem, eivada de metáforas, conotações, destaque a questões pitorescas, alusões e trocadilhos ${ }^{10}$ que carreiam consigo uma dimensão filosófica em geral, e epistemológica em particular. Tal linguagem está relacionada fundamentalmente com a temática que engendra a oportunidade de construir a narrativa: a epidemia. ${ }^{11}$

O instrumento de Boccaccio para a redenção das expressões mais significativas de uma cidade atingida pela peste é a narrativa, a qual assumiu uma função especial na filosofia moral inerente à produção literária desse autor. Em Decamerão, em particular, estabelece-se uma relação indissociável entre literatura e arte retórica por causa da intenção comunicativa e transitiva entre as personagens. No curso da interação comunicativa entre as personagens da obra florentina, emergem as pulsões e as indolências que envolvem a atmosfera da ação, as quais cooperam para mascarar a relação entre causa, motivação e persuasão do autor, e o efeito, alvo e a persuasão de seus leitores. Logo, a peste e a filosofia que a partir dela é compartilhada assume a discrição decorrente do jogo entre o gesto do artista ao apresentar a sua narrativa, e provoca efeitos nos pensamentos e práxeis de seus leitores, efeitos que são resultados da interação dos leitores com o artista do gesto, o próprio Boccaccio, por meio de sua obra. ${ }^{12}$ Logo, a filosofia moral que se depreende de Decamerão despista a origem dos signos provenientes da individualidade particular do autor, e mascara até mesmo a sua filiação filosófica, pois tanto o autor faz o papel de morto em sua escrita, ${ }^{13}$ quanto a sua filiação intelectual está disfarçada pela retórica. A filosofia é o seu meio subjacente à literatura, e a retórica inerente à narrativa é o seu veículo de persuasão dos leitores.

\footnotetext{
${ }^{8}$ GITTES, T. F. Boccaccio's Naked Muse: Eros, Culture, and the Mythopoeic Imagination. Toronto: University of Toronto Press, 2016, p. 21.

${ }^{9}$ A rejeição da ideia de Boccaccio como filósofo é enfatizada em: DE SANCTIS, F. Storia della letteratura italiana. Vol. I. Milano: BUR, 2006, p. 309-311; BRUNI, F. Boccaccio, l 'invenzione della letteratura mezzana. Bologna: Il Mulino, 1990, p. 263.

${ }^{10}$ ZACCARIA, V. Boccaccio narratore, storico, moralista e mitógrafo. Firenze: L.S. Olschki, 2001.

${ }^{11}$ Parece que Decamerão se inscreve em uma tradição literária que já conta com a obra latina Compilatio singulorum exemplorum, com os contos judaico-espanhóis de José Ibn Zabara, e com a obra Historia de la doncella Teodor. Nas três obras, há uma disputa sobre o conhecimento na forma literária de desafio a fím de se obter conhecimento prático para a vida cotidiana. Ver: FREEDMAN, A. "Il cavallo di Boccaccio: fonte, struttura e funzione dela metanovella di Madonna Oretta." In: Studi sul Boccaccio 9, 1975, p. 225-241 (especialmente, p. 231-232); COLLI, G. La nascita della filosofia. Milano: Adelphi, 1978, p. 75.

12 SCHOLLHAMMER, Karl. Além do visível: o olhar da literatura. Rio de Janeiro: 7Letras, 2007, p. 106.

${ }^{13}$ FOUCAULT, M. O que é um autor? In: FOUCAULT, M. Ditos e escritos III: Estética: literatura e pintura, música e cinema. Tradução de Inês Barbosa. Rio de Janeiro: Forense, 2011, p. 269.
} 
Há, no início de Decamerão, o recurso ao tema do deslocamento da cidade atingida pela peste para o campo. Quem faz a proposta de tal deslocamento no início da obra é Pampineia, que apresenta as condições éticas que justificam a sua fuga e a dos contadores de histórias de Florença, pois lhes dá uma motivação ideológica razoável, tornando a alternativa do êxodo algo possível, visto ser proveniente de uma "leggiadra onestà" (Decamerão I, Intr., 49). ${ }^{14}$ Logo, o Decamerão, obra de filosofia moral prática, não se compromete com uma sabedoria ascética, mas entende ser necessário preservar o conhecimento destinado a civilizar, tornando os possuidores de tal conhecimento capazes de viver juntos conforme os ideais da virtude cívica.

É inegável, porém, que se ignore um eco na proposta de Pampineia daquilo que pode ser encontrado em um autor muitas vezes visitado por Boccaccio, Cícero, que afirma:

Principio generi animantium omni est a natura tributum, ut se, vitam corpusque tueatur, declinet ea, quae nocitura videantur, omniaque, quae sint ad vivendum necessaria anquirat et paret, ut pastum, ut latibula, ut alia generis eiusdem. Commune item animantium omnium est coniunctionis appetitus procreandi causa et cura quaedam eorum, quae procreata sint.

Em primeiro lugar, a natureza dotou todas as espécies de criaturas vivas com o instinto de autopreservação, de evitar o que parece susceptível de causar danos à vida ou aos membros, e de obter e fornecer tudo o que é necessário para a vida - comida, abrigo e semelhantes. Uma propriedade comum a todas as criaturas é também o instinto reprodutivo (cujo propósito é a propagação da espécie) e também uma certa preocupação com os seus descendentes. (Cicero, De officiis 1.11$)^{15}$

O instinto de preservação, atributo da "razão natural", une-se à rejeição da desobediência das leis e da concessão aos enlevos carnais como motivos evocados por Pampineia a fim de fornecer subsídios morais para a fuga da cidade oprimida pela peste. Está em operação, portanto, um argumento que vislumbra a superioridade, que desencadeará um "occulto giudicio" diante do qual ninguém deve se surpreender:

Valorose donne, quanto più si parla de' fatti della Fortuna, tanto più, a chi vuole le sue cose ben riguardare, ne resta a poter dire; e di ciò niuno dee aver maraviglia, se discretamente pensa che tutte le cose, le quali noi scioccamente nostre chiamiamo, sieno nelle sue mani, e per conseguente da lei secondo il suo occulto giudicio, senza alcuna posa d'uno in altro e d'altro in uno successivamente, senza alcuno conosciuto ordine da noi, esser da lei permutate.

Senhoras nobres, por mais que possamos falar da obra da Fortuna, muito ainda resta a ser dito se apenas examinarmos os eventos corretamente, nem precisamos nos maravilhar, portanto, se considerarmos devidamente que todas as questões, que tolamente chamamos de nossas, estão em suas mãos e, portanto, sujeitas, de acordo com seu juízo oculto, a toda variedade de acaso e mudança sem nenhuma ordem discernível por nós. (Boccaccio, Decamerão II.3.4)

\footnotetext{
${ }^{14}$ Ver: CHERCHI, P. L'onestade e l'onesto raccontare del Decameron. Fiesole: Cadmo, 2004.

15 Todas as traduções são próprias do autor do artigo.
} 
Logo, a Fortuna é a agente da ordem inescrutável, da ius/lex naturalis, diante da qual a "razão natural" constitui um dispositivo epistemológico do qual Pampineia lança mão para que ela e os seus companheiros legitimem sua fuga, ao mesmo tempo em que se lançam à tarefa de interpretar o curso dos acontecimentos. ${ }^{16}$

\section{Sobre o escapismo e as epidemias (ou sobre a filosofia moral alienada)}

Pampineia é uma personagem-signo da reação de sublimação da disposição para o enfrentamento da condição epidêmica em prol da preservação do legado humano. Logo, ela é fruto de uma concepção que coloca o legado humano acima do humano propriamente dito, uma vez que não age para preservar quem engendra narrativas e lições, tornando-as o fim que se sobrepõe ao valor da vida de quem as proporcionou. Decamerão fala sobre a dezena de pessoas que conservou muitas lições para que se compreendesse que a peste inelutável é uma realidade fatal, não tanto para a vida, mas para a memória.

Noção semelhante perpassa o Canto Primeiro da Ilíada, que relata a peste que devastou parte do acampamento aqueu (Homero, Ilíada 1.8-117), mas dá ênfase à honra dos guerreiros e ao valor de seu butim, em vez de promover, por exemplo, o lamento pelas vidas que se perderam. ${ }^{17}$ É possível encontrar o mesmo em Heródoto - ou seja, não mais na epopeia, mas na historiografia. Xerxes e seu exército são acometidos de doenças enquanto eles fugiam, mas a ênfase da narrativa herodoteana está posta sobre a decisão do rei de deixar os guerreiros doentes para trás em favor do seu interesse de fugir com celeridade (Heródoto, Histórias 8.115.1-4).

Tanto a Ilíada quanto as Histórias mencionam a doença, mas colocam os doentes como pano de fundo de uma discussão sobre ảpetท́ (Ilíada) ou sobre a inferioridade do bárbaro/persa (Histórias). Ambos os textos influenciam outras narrativas sobre doenças cuja prioridade está nas atividades, conquistas ou interesses humanos, não nas medidas para preservação da vida, ou para controle da doença. Tito Lívio, em sua obra Ab urbe condita, é outro exemplo dessa tradição. Diante das catástrofes epidêmicas que fustigavam Roma, e que eventualmente são citadas em sua obra, ele tende a alegar aspectos religiosos, oráculos, contato com um corpo cívico estranho e atuação de líderes como fatores desencadeadores de doenças ( $A b$ Urbe Condita 2.34.5-6, 3.6.4-6, 3.9.6-12, 3.32.1-5, 4.9.1-3, 4.21, 4.25.1-8).

\footnotetext{
${ }^{16}$ MAZZOTTA, G. The World at Play in Boccaccio's Decameron. Princeton: Princeton University Press, 1986 , 221-222, 243-244; BARSELLA, S. “Boccaccio, i tiranni e la ragione naturale,” In: Heliotropia 12-13, 2015-2016, p. 131-163.

${ }^{17}$ KIBUUKA, B. G. L. Epidemias na Antiguidade. São Paulo: Fonte Editorial, 2020, p. 33-52.
} 
Os relatos dos eventos epidêmicos feitos por Tito Lívio costumam fazer alusões às consequências econômicas da doença, como a "pestilentia, inopia frugum" [com a peste, a falta de frutos] (Ab Urbe Condita 4.20.9); ou à proveniência externa da peste - "quia pestilentia populum invasit" [porque uma peste havia invadido o povo] (Ab Urbe Condita 4.21.2); ou ao fato da epidemia ser duradoura, como a "pestilentior inde annus" [pestilência no ano seguinte] (Ab Urbe Condita 4.21.14). As referências eventuais à tentativa de adquirir alimentos, às questões políticas relacionadas às eleições e ao governo, à religião e à guerra se assemelham muito aos problemas que explicam a ocorrência das pestilências (por exemplo, Ab Urbe Condita 4.25.1-8, que aborda a peste de Roma em 433 a.C.). Vê-se, portanto, que a tradição narrativa relacionada às pestilências passa longe da reflexão sobre a assistência solidária às vítimas, enfocando as causas da peste, as vicissitudes que ela desperta e as ações para preservação ética ou religiosa.

Um indício da alienação da questão está no silêncio dos textos filosóficos sobre a gestão de uma doença epidêmica com atenção especial no doente e no cuidado com a população vulnerável. O próprio termo epidemia, que é atestado em grego ( $\dot{\pi} \pi \delta \eta \mu i ́ \alpha)$, é proveniente do grego antigo e significa literalmente "no povo", "sobre o povo", sendo atestado em Platão (Leis 6.766c; Teeteto 173e; Banquete 172c; Parmênides 126b), Aristóteles (Política 2.1274a; 5.1313b; Constituição Ateniense 39) e Xenofonte (Ciropédia 7.5), porém nunca associado às doenças, mas a quem promove uma guerra (Aristófanes, Paz 1096-1098), ou sendo alusivo à reputação de alguém em contexto políade (Sófocles, Édipo Rei 494, 786). Mais tarde, no Império Romano, o termo ‘epidemia' passou a designar a condição de um estrangeiro residente (Marco Aurélio, Meditações 2.17), visitantes (em latim, os advenae romani, Atos dos Apóstolos 9.1-19) ou o advento da divindade sobre os mortais (Eusébio de Cesareia, História Eclesiástica 1.2). Logo, a liderança na vida das pessoas, o envolvimento em guerras civis, a reputação pública, as relações com estrangeiros eram 'epidemias', sendo a doença (em grego, vóøos; em latim, morbus, pestis ou aegror) o termo com sentido médico que é encontrado no Corpus Hippocraticum. A obra Epidemias (em latim, De morbis popularibus), do Corpus Hippocraticum, composta de sete livros, é a que utiliza o vocábulo 'epidemia' como algo do campo da saúde pública, e designativo da "doença do povo" (Epidemias 3.2.3; 3.2.12).

Foi apenas na Antiguidade Tardia que fontes passaram a abordar a peste sob uma nova estrutura, em que se compreende as ondas de uma epidemia, o conceito de praga e o impacto histórico de doenças epidêmicas. Foi nesse período que as interseções entre as doenças e a 
filosofia moral começaram a ser estabelecidas. ${ }^{18}$ Galeno, por exemplo, via a medicina dietética como um ramo da filosofia moral, de forma que os erros no modo de vida, a ignorância ou a intemperança não apenas provocavam doenças internas, como legitimavam a posição social e intelectual dos médicos e das pessoas saudáveis em detrimento dos doentes. ${ }^{19}$ Galeno fala a respeito da possibilidade de uma cura 'ética', que pertence ao campo da terapia filosófica, em De affectuum renibus insidentium dignotione et curatione e em De moribus. ${ }^{20} \mathrm{Em}$ De symptomatum differentiis, Galeno aborda a doença mental e suas implicações. Como foi destacado por Christopher Gill, a perspectiva de Galeno aqui parece fortemente relacionada ao discurso platônico e aristotélico sobre a importância da educação e do treinamento inicial e da subsequente habituação para a excelência ética. ${ }^{21}$

Os impactos de tal relação entre doença e ética podem ser vislumbrados em Gregório. Ao escrever sobre o surto epidêmico em Arles, em 543, Gregório informa sobre o pedido da cidade de Clermont para que houvesse uma procissão religiosa contra Arles, um indício da noção da existência de uma geografia da praga que está de alguma forma condicionada à conduta praticada em determinadas espacialidades (Gregório de Tours, Libri historiarum 10.4.5).

É possível constatar a ampliação dessa abordagem ética e geográfica das doenças nas deliberações do Terceiro Concílio de Latrão, o qual estabeleceu um ritual de separação e identificação de leprosos: o leproso deveria se ajoelhar diante do altar da igreja sob um pano preto, portando sobre o rosto um véu preto. Deveria também andar com um manto, com chapéu de abas largas, bermudões escuros e túnicas bordadas com a imagem de São Lázaro, além de luvas nas mãos e um cordão preso junto ao corpo, trazendo um corno ou uma matraca. ${ }^{22}$ Nessa época, há uma intersecção entre a perspectiva com que eram vislumbrados os judeus e os muçulmanos, as prostitutas e os homossexuais, caso adoecessem, e os leprosos: todos esses eram considerados culpados por desvios de conduta, tornando-se alvos do castigo divino. ${ }^{23}$

\footnotetext{
${ }^{18}$ BIRABEN, J. N.; LE GOFF, J. “The Plague in the Early Middle Ages.” In: FOSTER, R.; RANUM, O. (eds.). Biology of Man in History. Baltimore: Johns Hopkins University Press, 1975, p. 48-80. Ver ainda: LADURIE, E. L. R. "Un concept: L'unification microbienne du monde (XIVe 21-XVIIe siècles).” In: Schweizerische Zeitschrift für Geschichte 23 (4), 1973, p. 627-696.

${ }^{19}$ SINGER, P. N. "Galen's Pathological Soul: Diagnosis and Therapy in Ethical and Medical Texts and Contexts." In: THUMIGER, C.; SINGER, P. N. Mental Illness in Ancient Medicine: From Celsus to Paul of Aegina. Leiden: Brill, 2018, p. 381-420.

${ }^{20}$ LIN, L. "Galen on to kalon and to agathon in De moribus." In: Greek, Roman, and Byzantine Studies 58, 2018, p. $77-101$.

${ }^{21}$ GILL, C. Naturalistic Psychology in Galen and Stoicism. Oxford: Oxford University Press, 2012, p. 221-227, 249-250, 257-262.

${ }^{22}$ LE GOFF, J. A civilização do ocidente medieval. Vol. 1. Lisboa: Imprensa Universitária, 1984; FROHN, W. Der aussatz im Rheinland; sein vorkommen und seine bekämpfung. Jena: Gustav Fischer, 1933.

${ }^{23}$ Ver: RICHARDS, J. Sexo desvio e danação: as minorias na Idade Média. Rio de Janeiro: J. Zahar, 1993.
} 
O poder para a cura e afastamento das consequências da moral que, segundo se cria à época, deixava mais susceptível às doenças, está na atuação caridosa de reis medievais em favor dos enfermos nos séculos XI, XII e XIII. Foi uma época de reis considerados ao mesmo tempo taumaturgos e santos, como Robert II, o Piedoso, e Luís IX da França; e Eduardo, o Confessor, e Henrique III da Inglaterra. ${ }^{24}$ Os que não podiam apelar aos reis recorriam à medicina popular, constituída de uma mescla entre religião, magia, filosofia e tradição. Os procedimentos eram tanto intervenções no corpo, como sangramento e purga, quanto os provenientes da fé e do rito, como a linguagem arcana, as fórmulas religiosas, os encantamentos, os apelos aos poderes da natureza, aos demônios ou aos santos.

A perspectiva coletivista de mal, que é a um só tempo biológica e social, sendo este mal causa daquele; bem como a dimensão religiosa dada à possibilidade de prevenção e cura, além da medicina popular ineficaz constituíram um conjunto que serviu de obstáculo para o tratamento direto das vítimas das epidemias na Idade Média. Isso não se deu apenas por causa do colapso sanitário, ou por causa da falta de alternativas devido ao desenvolvimento precário da medicina. Houve uma filosofia moral que via nos eventos epidêmicos a possibilidade de formação da justificativa para a alienação de uma elite promissora, o gérmen de uma sociedade ideal, que aproveita a doença do corpo e da conduta para reorganizar a vida coletiva. A Pampineia de Decamerão é o vetor do escapismo moralmente justificado, com motivações culturais que se restringem à conservação da memória do povo sem precisar lidar com o próprio povo, alvo de desapreço. Funda-se, na experiência epidêmica, uma filosofia moral agregada a um texto literário que valida o escapismo e a interação solidária entre os considerados viáveis, os quais se tornam guardiães plenipotenciários da memória coletiva em um castelo habitado por privilegiados exemplares.

\section{Epidemias e filosofias: o legado do escapismo utilitário e a sua crítica na contemporaneidade}

A mescla entre religião, valorização da tradição aristocrática e apego à cultura popular sem consideração à saúde do povo provocou o fenômeno da adoção de discursos subescritores da alternativa escapista às epidemias. Tal perspectiva medieval, presente em Decamerão, deixou reflexos de si especialmente nas filosofias utilitaristas, cujo intento é a promoção do privilegiamento do interesse coletivo - o qual, geralmente, corresponde à busca do interesse de

\footnotetext{
${ }^{24}$ BLOCH, M. Os Reis Taumaturgos: o caráter sobrenatural do poder régio: França e Inglaterra. São Paulo, Cia das Letras, 1999.
} 
classes privilegiadas - em detrimento do bem-estar individual. ${ }^{25}$ A teoria político-filosófica utilitarista e o seu apelo em favor do chamado bem maior nem sempre identificam tal bem com a eliminação da doença com o melhor resultado possível para a maioria das pessoas. Para que haja algum vislumbre disso, é necessário confrontar às perspectivas utilitárias a centralidade da dignidade humana.

As perspectivas contratualistas de Hobbes, Locke, Rousseau e Kant, somadas à perspectiva de Rawls de que a justiça é um objetivo do contrato social, ${ }^{26} \mathrm{em}$ favor do bem-estar mútuo, são alternativas ao utilitarismo coletivista. Tais perspectivas podem ser resumidas na noção de que o Estado deve promover o tratamento, em uma epidemia, até mesmo daqueles que podiam estar muito doentes para serem salvos, ainda que os recursos médicos se esgotem, se tornando indisponíveis para aqueles que poderiam ser salvos a posteriori. Em tal concepção de direitos humanos e individuais, abdica-se da "via cinzenta" 27 da dúvida em salvar a vida para a centralidade da preservação da existência devido ao valor inerente de cada pactuante. Essa ideia também veta a iniciativa de abandonar ou submeter pessoas à dor intensa e prolongada, à humilhação, ao medo debilitante, às doenças incapacitantes e desfigurantes, e ao isolamento punitivo prolongado.

As iniciativas de abandono ou atuação sistemática contra grupos específicos com o intuito de garantir a preservação da possibilidade do bem coletivo estão ligadas ao que Kant chamou de "mal radical", ${ }^{28}$ tendência a abrir mão de preservar a vida de forma universal, o que culmina muitas vezes em genocídio. A alegação da inexistência da intenção de matar, da incapacidade de distinguir o certo do errado diante do poder e da estrutura de poder, ou a

\footnotetext{
${ }^{25}$ A premissa do utilitarismo é a obtenção da maior felicidade para o maior número de pessoas, sendo objeto de disputa entre Bentham e Mill se felicidade coincide ou não com a ideia de prazer. O utilitarismo tende a procurar maximizar a satisfação das preferências autônomas dos indivíduos, pois essa seria a melhor maneira de maximizar a felicidade geral. Em relação à ética médica, o utilitarismo está no horizonte de possibilidades no tratamento de enfermidades e até no enfrentamento de pandemias e epidemias. Ver: SWALES J. D. "Medical ethics: some reservations." In: Journal of Medical Ethics 8, 1982, p. 117-119; BROOKS, S. A. "Dignity and cost effectiveness: a rejection of the utilitarian approach to death." Journal of Medical Ethics 10, 1984, p. 148-151; MILL, J. S. "On liberty." In: WARNOCK, M. (ed.). Utilitarianism. Glasgow: William Collins, 1962, p. 260. SINGER, P. Practical ethics. Cambridge: Cambridge University Press, 1982, p. 80.

${ }^{26}$ Afirma RAWLS: "Each person possesses an inviolability founded on justice that even the welfare of society as a whole cannot override [...]" ["Cada pessoa possui uma inviolabilidade fundada na justiça que nem mesmo o bem-estar da sociedade como um todo pode ignorar (...)"] (RAWLS, J. A Theory of Justice. Cambridge: Harvard University Press, 1999, p. 3).

${ }^{27}$ LEVI, P. The Drowned and the Saved. New York: Vintage, 1989, p. 36-69.

${ }^{28}$ Kant, em Religião dentro dos limites da mera Razão, cunha a expressão "mal radical", uma exacerbação da noção de mal kantiana, a transgressão relacionada arbítrio no uso da liberdade. O mal é uma inclinação natural e inata para o mal presente na raiz do ato, sendo o mal que está presente na intenção de uma ação. Ver: BERNSTEIN, R. J. Radical Evil: A Philosophical Interrogation. Cambridge: Polity, 2002; GUYER, P. "The Strategy of Kant's Groundwork." In: GUYER, P. Kant on Freedom, Law, and Happiness. Cambridge: Cambridge University Press, 2000, p. 207-231.
} 
alegação de ignorância ${ }^{29}$ não constituem justificativas aceitáveis quando se vislumbra a preservação da vida e da dignidade de cada pessoa como respostas inescapáveis nas práxeis da gestão de crises de saúde, de pandemias e epidemias.

Kant, na obra Religião dentro dos limites da mera razão, ofereceu um guia interpretativo para o envolvimento humano com o mundo, e para a discussão da estrutura moral do mal. Retomando o conceito de mal radical, Arendt alega que a desumanização de vítimas enquanto elas estão vivas e a subtração de sua dignidade são indícios de desumanização dos que lhes viram as costas. Eis o que se chama aqui de 'síndrome de Pampineia', que esvazia a solidariedade com as pessoas, enxerga nelas a justificativa para a postura não solidária e aceita o dano radical previsível.

Jürgen Habermas defendeu o princípio kantiano contra o utilitarismo ao afirmar:

\begin{abstract}
Im bisherigen Verlauf der Krise konnte man und kann man in manchen Ländern Politiker beobachten, die zögern, ihre Strategie an dem Grundsatz auszurichten, dass die Anstrengung des Staates, jedes einzelne Menschenleben zu retten, absoluten Vorrang haben muss vor einer utilitaristischen Verrechnung mit den unerwünschten ökonomischen Kosten, die dieses Ziel zur Folge haben kann. Wenn der Staat der Epidemie freien Lauf ließe, um schnell eine hinreichende Immunität in der gesamten Bevölkerung zu erreichen, nähme er das vermeidbare Risiko des voraussehbaren Zusammenbruchs des Gesundheitssystems und damit einer relativ höheren Anteil an Toten billigend in Kauf.
\end{abstract}

No curso da crise até agora, pode-se observar políticos em alguns países que hesitam em basear sua estratégia no princípio de que os esforços do Estado para salvar todas as vidas humanas devem ter prioridade absoluta sobre a compensação utilitária contra os custos econômicos indesejáveis que esse objetivo pode acarretar. Se o estado deixasse a epidemia com as rédeas soltas para que ela alcançasse rapidamente imunidade suficiente de toda a população, ele aceitaria o risco evitável de um colapso previsível do sistema de saúde e, portanto, uma proporção relativamente maior de mortes. $^{30}$

Habermas demonstra que inversões utilitárias é que criam o dilema saúde versus economia, de forma que o interesse instrumental em manter a economia funcionando em detrimento da vida é uma inversão. Tal inversão é análoga à proposta por Pampineia: preservar a própria vida e cultura popular sem povo por meio da fuga é análogo a preservar a economia desprezando aquele que produz, vende e compra, deixando-o à mercê da morte.

As práticas de preservação da vida transformadas em instrumentos de vigilância exerceram muita influência no pensamento de Foucault. A sua noção de panopticismo, ou seja, a criação de mecanismos de disciplina, rituais de exclusão, supervisão e aferimento se relaciona às doenças e ao enfrentamento delas segundo a lógica utilitária. Para Foucault, foi a peste que

\footnotetext{
${ }^{29}$ ARENDT, H. Eichmann in Jerusalem: A Report on the Banality of Evil. New York: Penguin, 1994, p. 287.

${ }^{30}$ SCHWERING, M. Jürgen Habermas über Corona: „So viel Wissen über unser Nichtwissen gab es noch nie“. In: Frankfurter Rundschau, 10/4/2020. Disponível em: https://www.fr.de/kultur/gesellschaft/juergen-habermascoronavirus-krise-covid19-interview-13642491.html em 21 de março de 2021.
} 
trouxe consigo a noção de quarentena por bloqueio, e que é gérmen da sociedade disciplinada e disciplinadora, cujo bem-estar almejado privilegia os que detêm o poder de vigiar e o exercem para coagir os demais em nome de todos. ${ }^{31}$ Em tal sociedade disciplinada e disciplinadora, a militarização da política, as medidas de controle com objetivos econômico-financeiros, as limitações da liberdade em nome da segurança e o boicote às medidas de proteção de saúde dos mais vulneráveis se enquadram no que Agamben chama de "securitização biopolítica", que produz o estado de exceção permanente. ${ }^{32}$

\section{À guisa de conclusão: na epidemia, a defesa da vida}

Episódios epidêmicos ou pandêmicos são oportunidades de reajuste do tecido social, mediante o fortalecimento das noções de dignidade e direitos universais. As contingências próprias de um período epidêmico ou pandêmico também servem como ocasiões férteis para a manifestação do que há de pior nas sociabilidades. A memória social das epidemias da Antiguidade e da Idade Média teceram o pano-de-fundo dos relatos de doenças mortais e que atingiram muitas pessoas: elas deixaram atrás de si uma concepção reforçada de impotência, de aproveitamento das oportunidades de autopreservação e a implementação de vigilância, segregação, exclusão, militarização, transferência de renda.

Para viabilizar as assimetrias é que são reforçadas em período as sociabilidades precarizadas em prejuízo da vida humana e do patrimônio cultural. $\mathrm{O}$ que disso resulta são práticas socioculturais reificadas. Por outro lado, uma seleção mediada pelos interesses de grupos hegemônicos tende a descartar a vida em favor de algum bem simbólico que é percebido no panóptico, sequestrado na securitização biopolítica e valorizado acima da vida no discurso público. Logo, a declaração sem sentido e sem mérito, "mais importante que a vida, é a liberdade", ${ }^{33}$ por exemplo, é resultado da alienação da vida. Só assim se torna admissível dizer, sem ser muito convincente, que mortos podem partilhar a liberdade. Essas inversões se dão em detrimento das classes populares, da vida dos que adoecem.

A hierarquia que se estabelece no controle de uma epidemia entre os que têm o direito e as condições para sobreviver e aqueles aos quais é sonegado esse direito é a evidência mais clara da permanência da síndrome de Pampineia. Herdeira do descuido com a vida dos nãomembros da aristocracia na Antiguidade, e das filosofias morais cristã e de Galeno, que

\footnotetext{
${ }^{31}$ FOUCAULT, M. Discipline and Punish: The Birth of the Prison. London: Penguin Books, 1977, p. 198.

${ }^{32}$ AGAMBEN, G. State of Exception. Chicago: Chicago University Press, 2005. Ver ainda: AGAMBEN, G. Homo Sacer: Sovereign Power and Bare Life. Stanford: Stanford University Press, 1998.

${ }^{33}$ MENDONÇA, A. "'Existe algo a perder mais importante que a vida: a liberdade', diz Bolsonaro". In: Correio Braziliense 9/3/2021. Disponível em: https://www.correiobraziliense.com.br/politica/2021/03/4911048-existealgo-a-perder-mais-importante-que-a-vida-a-liberdade-diz-bolsonaro.html em 21 de março de 2021.
} 
relacionam doenças ao caráter, a síndrome de Pampineia se traduziu na modernidade no utilitarismo autoritário. Sua presença na literatura a popularizou, o que faz dela um obstáculo presente no imaginário coletivo às medidas que consideram cada pessoa digna da vida e alvo do cuidado que viabiliza a sua vida. Os dispositivos estatais dispostos para vigiar, controlar e punir -o mal radical, a securitização biopolítica e o estado de exceção permanente precisam ser identificados e desbaratados, em favor da dignidade da vida: de toda e qualquer vida humana, em qualquer tempo e espaço.

\section{REFERÊNCIAS BIBLIOGRÁFICAS}

AGAMBEN, G. Homo Sacer: Sovereign Power and Bare Life. Stanford: Stanford University Press, 1998.

AGAMBEN, G. State of Exception. Chicago: Chicago University Press, 2005.

ANDREI, F. Boccaccio the Philosopher: An Epistemology of the Decameron. Cham: Palgrave Macmillan, 2017.

ARENDT, H. Eichmann in Jerusalem: A Report on the Banality of Evil. New York: Penguin, 1994.

BARSELLA, S. "Boccaccio, i tiranni e la ragione naturale," In: Heliotropia 12-13, 2015-2016, p. 131-163.

BASSETT, S. (ed.). Death in Towns: Urban Responses to the Dying and the Dead, 100-1600. New York: Leceister University Press, 1992.

BERNSTEIN, R. J. Radical Evil: A Philosophical Interrogation. Cambridge: Polity, 2002.

BLOCH, M. Os Reis Taumaturgos: o caráter sobrenatural do poder régio: França e Inglaterra. São Paulo, Cia das Letras, 1999.

BROOKS, S. A. "Dignity and cost effectiveness: a rejection of the utilitarian approach to death." Journal of Medical Ethics 10, 1984, p. 148-151; MILL, J. S. "On liberty." In: WARNOCK, M. (ed.). Utilitarianism. Glasgow: William Collins, 1962, p. 260. SINGER, P. Practical ethics. Cambridge: Cambridge University Press, 1982, p. 80.

BRUNI, F. Boccaccio, l 'invenzione della letteratura mezzana. Bologna: Il Mulino, 1990.

CARMICHAEL, A. G. Plague and the Poor in Renaissance Florence. Cambridge: Cambridge University Press, 1986.

CHERCHI, P. L'onestade e l'onesto raccontare del Decameron. Fiesole: Cadmo, 2004.

COLLI, G. La nascita della filosofia. Milano: Adelphi, 1978.

DE SANCTIS, F. Storia della letteratura italiana. Vol. I. Milano: BUR, 2006.

FOSTER, R.; RANUM, O. (eds.). Biology of Man in History. Baltimore: Johns Hopkins University Press, 1975. 
FOUCAUlT, M. Discipline and Punish: The Birth of the Prison. London: Penguin Books, 1977.

FOUCAULT, M. Ditos e escritos III: Estética: literatura e pintura, música e cinema. Rio de Janeiro: Forense, 2011.

FREEDMAN, A. "Il cavallo di Boccaccio: fonte, struttura e funzione dela metanovella di Madonna Oretta.” In: Studi sul Boccaccio 9, 1975, p. 225-241.

FROHN, W. Der aussatz im Rheinland; sein vorkommen und seine bekämpfung. Jena: Gustav Fischer, 1933.

GILL, C. Naturalistic Psychology in Galen and Stoicism. Oxford: Oxford University Press, 2010 .

GITTES, T. F. Boccaccio's Naked Muse: Eros, Culture, and the Mythopoeic Imagination. Toronto: University of Toronto Press, 2016.

GUYER, P. Kant on Freedom, Law, and Happiness. Cambridge: Cambridge University Press, 2000 .

KIBUUKA, B. G. L. Epidemias na Antiguidade. São Paulo: Fonte Editorial, 2020.

LADURIE, E. L. R. "Un concept: L'unification microbienne du monde (XIVe 21-XVIIe siècles).” In: Schweizerische Zeitschrift für Geschichte 23 (4), 1973, p. 627-696.

LE GOFF, J. A civilização do ocidente medieval. Vol. 1. Lisboa: Imprensa Universitária, 1984.

LEVENSETIN, J. “Out of Bounds: Passion and Plague in Boccaccio's Decameron.” In: Italica 70 (3), 1996, p. 313-335.

LEVI, P. The Drowned and the Saved. New York: Vintage, 1989.

LIN, L. "Galen on to kalon and to agathon in De moribus." In: Greek, Roman, and Byzantine Studies 58, 2018, p. 77-101.

MARINO, L. "Prometheus, or the Mythographer's Self-Image." In: Studi sul Boccaccio 12, 1980, p. 263-273.

MAZZOTTA, G. The World at Play in Boccaccio's Decameron. Princeton: Princeton University Press, 1986.

MENDONÇA, A. “"Existe algo a perder mais importante que a vida: a liberdade', diz Bolsonaro". In: Correio Braziliense 9/3/2021. Disponível em: https://www.correiobraziliense.com.br/politica/2021/03/4911048-existe-algo-a-perder-maisimportante-que-a-vida-a-liberdade-diz-bolsonaro.html em 21 de março de 2021.

RAWLS, J. A Theory of Justice. Cambridge: Harvard University Press, 1999.

RICHARDS, J. Sexo desvio e danação: as minorias na Idade Média. Rio de Janeiro: J. Zahar, 1993.

SCHOLLHAMMER, Karl. Além do visível: o olhar da literatura. Rio de Janeiro: 7Letras, 2007.

SCHWERING, M. Jürgen Habermas über Corona: „So viel Wissen über unser Nichtwissen gab es noch nie“. In: Frankfurter Rundschau, 10/4/2020. Disponível em: https://www.fr.de/kultur/gesellschaft/juergen-habermas-coronavirus-krise-covid19-interview13642491.html em 21 de março de 2021. 
SWALES J. D. "Medical ethics: some reservations." In: Journal of Medical Ethics 8, 1982, p. 117-119.

THUMIGER, C.; SINGER, P. N. Mental Illness in Ancient Medicine: From Celsus to Paul of Aegina. Leiden: Brill, 2018.

USHER, J. “Ars Moriendi in the Decameron.” In: The Modern Language Review 81 (3), 1986, p. 621-632.

ZACCARIA, V. Boccaccio narratore, storico, moralista e mitógrafo. Firenze: L.S. Olschki, 2001. 